OPEN ACCESS

Edited by:

Pasquale De Palo,

University of Bari Aldo Moro, Italy

Reviewed by:

Morris Villarroel,

Polytechnic University of

Madrid, Spain

Chong Wang,

lowa State University, United States

Bonnie M. Perdue,

Agnes Scott College, United States

*Correspondence:

Temple Grandin

cheryl.miller@colostate.edu

Specialty section:

This article was submitted to Animal Welfare and Policy,

a section of the journal Frontiers in Animal Science

Received: 19 July 2021

Accepted: 06 September 2021

Published: 07 October 2021

Citation:

Grandin T (2021) The Visual, Auditory, and Physical Environment of Livestock

Handling Facilities and Its Effect on

Ease of Movement of Cattle, Pigs, and

Sheep. Front. Anim. Sci. 2:744207.

doi: 10.3389/fanim.2021.744207

\section{The Visual, Auditory, and Physical Environment of Livestock Handling Facilities and Its Effect on Ease of Movement of Cattle, Pigs, and Sheep}

\author{
Temple Grandin* \\ Department of Animal Science, Colorado State University, Fort Collins, CO, United States
}

The visual, auditory, and physical environment livestock are handled in will have an effect on the ease of movement through races and corrals that are used for veterinary treatment, loading trucks or at slaughter houses. When livestock refuse to move easily through a handling facility, people are more likely to use electric goads (prods) or other aversive methods to move them forward. This is a major animal welfare concern. Modification of the environment can improve livestock movement and reduce aversive handling methods. In existing facilities used for handling cattle, pigs or sheep, simple changes such as, adding a light to a dark race entrance or reducing loud intermittent noise may improve livestock movement. Eliminating distractions such as, a noisy truck near a lairage can also facilitate cattle movement and reduce stopping or turning back. In an outdoor facility, sharp shadows on the floor were more likely to be associated with cattle stopping compared to no shadows or soft faint shadows. The installation of small solid walls to prevent approaching animals from seeing either moving equipment, vehicles or people in front of them may also improve forward livestock movement. Non-slip flooring is essential to prevent slipping and falling during handling. Rebuilding or completely redesigning an existing facility is often not required. Outcome based indicators should be used to assess continuous improvements in handling. Some of the commonly used measurable of handling are slipping and falling, stopping, turning back, vocalization during handling and electric prod use. Collecting data both before and after an environmental modification can be used to determine its effectiveness.

Keywords: handling, environment, balking, electric goad, animal welfare

\section{INTRODUCTION}

When livestock refuse to move easily through a handling facility, handlers are more likely to use electric prods to move them (Grandin, 2001; Hultgren et al., 2020; Willson et al., 2021). Electric prod use will increase cortisol levels in cattle and lactate levels in pigs (Benjamin et al., 2001; Edwards et al., 2010; Hemsworth et al., 2011). The use of electric prods, hitting with sticks, and other aversive methods for moving animals are also a major welfare concern (Laven and Jermy, 2018; Sanchez-Hidalgo et al., 2020). The author describes how the immediate environment around an animal, as well as handling practices and facilities, can affect livestock movement through veterinary facilities, truck loading ramps, and slaughter houses. The emphasis will be on the visual, auditory, 
and physical environment. Stress and handling issues associated with the thermal environment will not be covered. This article contains information from both the scientific literature and the author's experiences.

This article will help explain why livestock will sometimes move easily and quietly through a handling facility and other times, they may constantly refuse to move forward, stop, or turn around. Often simple changes can be made to improve animal movement (Pereira-Lima et al., 2018). In an existing veterinary facility, slaughter plant or truck loading system, changes in lighting or flooring are often effective. (Hitchcock and Hutson, 1979; Hutson, 1981; Grandin, 2001). Rebuilding or redesigning an existing facility may not be required (Grandin, 2001). The first section of this article will explain how lighting, noise, flooring and changes in the environment may either improve or impede animal movement through a handling facility. Proper training of people in stockman ship is also essential (Ceballos et al., 2018). The second section will cover other factors that may make livestock difficult to move such as, the condition of the animals and their previous experiences with being handled.

\section{THE EFFECTS OF THE VISUAL ENVIRONMENT ON LIVESTOCK MOVEMENT THROUGH HANDLING FACILITIES}

\section{Effects of Sharp Shadows, Illumination, Dark Buildings, and Adding Lighting on Livestock Movement}

Sharp shadows, reflections, and other lighting problems in a handling facility can slow down the movement of cattle and pigs (Grandin, 1982; Klinglmair et al., 2011; Willson et al., 2021). There are differences in the types of lighting problems that may occur in outdoor and indoor facilities. In outdoor handling races and alleys, sharp shadows cast by a bright sun may increase the percentages of cattle balking and stopping. Balking is a term that is used when an animal stops and refuses to move forward when urged by a handler. During vehicle unloading in an outdoor facility, sharp high contrast shadows caused more cattle balking compared to no shadows or shadows with soft contrast (Willson et al., 2021). Figure 1 shows sharp shadows cast by the bars of the fence in a sheep facility. Piglets were also more likely to have a negative response to black and white stripes that created sharp contrast (Tanida et al., 1996). A survey of six sheep transporter drivers in Australia indicated that distractions, such as, shadows, were important problems that had a detrimental effect on handling (Burnard et al., 2015). The author has observed that a single bright sunbeam shining through a hole in a roof was associated with cattle stopping. This may explain why livestock sometimes move easily through a race or alley and at other times the animals will be difficult to move. This may occur because sometimes the sunbeam is present and at other times, it is absent. Stookey and Watts (2014) found that when cattle were given a choice in a Y-maze, the animals were more likely to choose the race where they could see light through the side of it. A common problem is cattle stopping and refusing to enter a building from

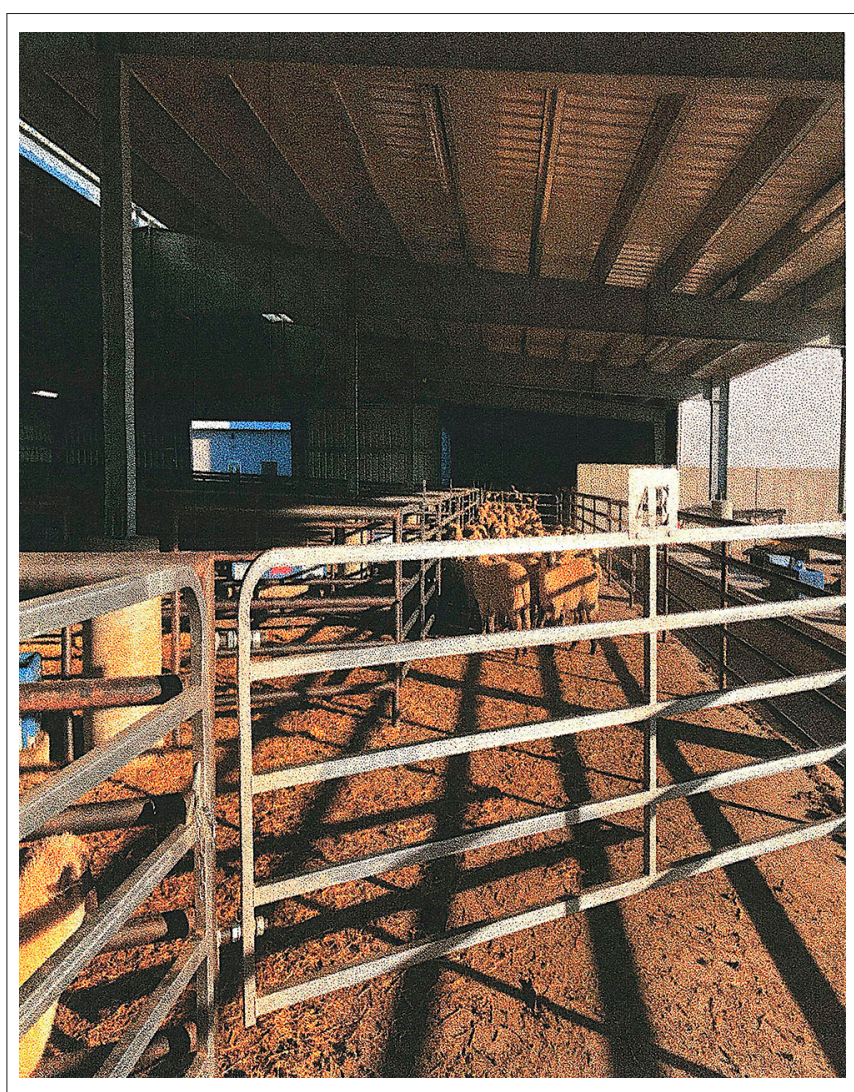

FIGURE 1 | Sharp shadows are more likely to cause animals to stop and refuse to move. When the sheep left the pens to enter the alley, some of them jumped over the shadows. Cattle and pigs are more likely to react by stopping.

an outdoor pen or corral. The author has observed that this problem is often worse on bright sunny days due to the "dark movie theater" effect. At night, the author has observed that they will often enter the same building easily, because the inside of an illuminated building is now brighter than the outside. In several large cattle veterinary handling systems, the author has improved cattle movement on bright sunny days by removing the back wall of the building and replacing it with white translucent plastic. This allowed ample natural light to enter the building.

In facilities that are completely indoors such as, slaughter plants, auctions and shearing sheds, lamps can be placed on dark race entrances to attract cattle, pigs, and sheep into them (van Putten and Elshof, 1978; Hitchcock and Hutson, 1979; Grandin, 1982, 2001; Tanida et al., 1996). Adding a lamp at a dark indoor race entrance reduced the use of electric prods from $38 \%$ of the pigs to $4 \%$ (Grandin, 2021). Livestock have a natural tendency to move toward a lighted area. In outdoor handling systems, the author has observed that they will not approach when either a rising or setting sun is shining directly into their eyes. Klinglmair et al. (2011) found that reflections and glare on wet floors increased the frequency of balking. Problems with stopping, balking and refusal to move due to lighting problems are most likely to occur in animals who are seldom handled in a particular facility. The author has observed in dairies, that a new 
heifer will stop at a shadow or a sunbeam the first few times she enters the milking parlor. An experienced cow has learned that the shadow and it is safe to walk over it.

\section{Effects of Seeing People, Other Animals, Visual Distractions and Changes in Flooring}

There are numerous visual distractions that are associated with livestock stopping or turning back during movement through a handling system. Seeing visible people up ahead can cause problems such as, animals stopping or turning back. However, when sheep see other sheep in front of them, they are often more willing to move through a single file race. Franklin and Hutson (1982) found that sheep are more willing to move toward either a picture of sheep or fake sheep if it is facing either away from them or sideways. A sheep facing them may be perceived as a threat. Cattle that were held in a squeeze chute (crush) remained calmer when a small solid shield was installed to prevent them from seeing a person who was administering an injection (Muller et al., 2008). Pereira-Lima et al. (2018) found that removing distractions improved cattle movement. In a large slaughter plant, a solid side on the single file race improved cattle movement (Ercolano, 2018). Stock people working with livestock should remove distractions such as, moving dangling chains, coats hung on fences, or a paper cup on the floor. Removal of distractions can improve animal movement (Grandin, 1996, 2021). Stock people who load sheep onto trucks report that removing distractions is important (Burnard et al., 2015).

Abrupt changes in the flooring surface the animals are walking on may cause them to stop (Kilgour, 1971; Hutson, 1981). Common problems observed by the author are changing from a dirt surface to a concrete surface. A simple method to improve movement is to sprinkle dirt on the junction between the two different type of surfaces. This reduces the visual contrast between the two different surfaces. Another common flooring change is moving from a concrete floor to a metal floor in single animal scales, hoof trimming tables or stun boxes. When approaching cattle, pigs or sheep stop at either a shadow or a change in flooring, the leader will often stop and put its head down. Ron Gill at Texas A and M explains that handlers should wait for the animal to raise its head up before attempting to move the animals forward.

\section{Depth Perception and Livestock Movement}

Animals can definitely perceive depth (Lemmon and Patterson, 1964). Since they have wide panoramic vision, it is likely that the reason they stop and put their heads down to look at a shadow or change of flooring is due to poor depth perception. In handling facilities that are raised above the floor, cattle will balk and refuse to move if they perceive the visual cliff effect Cattle were more willing to enter a center track conveyor restrainer in an abattoir when a false floor was installed to prevent them from seeing a 2 meter drop under the conveyor (Grandin, 2001). In sheep facilities where sheep are moved over a raised floor they can see through, adjustment of lighting and the direction of the grating will prevent the sheep form seeing the visual cliff effect (Hutson, 1981). If the grating is made from wood slats, the sheep are more likely to move easily if they walk across the slats (Hutson,
1981). Hutson (1981) also suggests closing up the side walls of an elevated shearing shed to prevent sheep form seeing light shining up from under the floor.

\section{Livestock Perception of Small Visual Changes in the Environment}

People often ask the author why livestock that had previously moved through a race or alley easily are now stopping and refusing to move. It is usually due to something that has changed that people did not notice. The author observed that at the experiment station at Colorado State University, that the cattle started stopping and refusing to move through the single file race. The cause of the problem was a new shiny highly reflective fuel tank that had been installed near the race. On a sunny day, there was a big reflection on the top of the tank. Vehicles parked alongside a race or livestock scale may also make animals balk and stop. Some scientists may dismiss these observations as anecdotal so the author decided to have her student conduct an experiment to determine how an animal may perceive a change in a previously familiar environment. People who ride horses will often say that the horse spooked and threw the rider for no reason. Spooking occurs when a horse suddenly and unexpectedly has a fear reaction that throws the rider (Carmargo et al., 2018). It is a major cause of horse accidents (Carmargo et al., 2018). It is likely that there was a change in the environment that the rider did not notice Corgan et al. (2021) habituated young colts and fillies that were trained to lead to a children's plastic playset. It was brightly colored and had a small swing and slide for a toddler each horse was walked by the playset 15 times until there was no reaction. The behaviors that were measured were stopping, quickly raising up the head, and nostrils flaring. When the playset was turned $90^{\circ}$, the horses reacted as if it was something new. This study was conducted with the horses walking because it would have been dangerous at higher speeds. Hawson et al. (2010) reported that danger to a rider increases when horses are ridden at faster speeds. The shape of the child's slide was totally different when the toy was rotated. Animals can be easily habituated to a novel object. Monk et al. (2018) reported that when a novel traffic cone was first placed next to the entrance of a race, it made it more difficult to move cattle into the race. After multiple trips through the race, the heifers acclimated to the traffic cone.

\section{EFFECTS OF NOISE AND SOUND}

Cattle and other livestock are sensitive to noise Pajor et al. (2003) reported that shouting at cows close to their ear was as stressful as electric prods. Waynert et al. (1999) reported that the sounds of people yelling and whistling was more stressful than gates clanging and banging. In another study, Hemsworth et al. (2011) found that shouting at cattle increased cortisol levels and normal conversation between people had no effect. Some commercial handling systems are extremely noisy and the loud sound may be up to 99-115 dB (Lyvers, 2013). Loud sounds over $85 \mathrm{~dB}$ had a greater effect on heartrate.

Intermittent loud sounds are more likely to make cattle or pigs react compared to a continuous sound (Talling et al., 1998; Lanier 
et al., 2000). The author has observed that sudden air hissing from the exhaust parts of pneumatic cylinders may stop movement of cattle through a race (Grandin, 1996). This problem can be easily mitigated by installing silencer devices. Lisa McLerie, an abattoir manager in Australia, informed the author that removing a loud siren reduced blood lactate.

Willson et al. (2021) studied cattle movement through a small abattoir. When a large noisy truck was parked alongside the lairage pens, the percentage of cattle that refused to move from the lairage into an alley greatly increased (Willson et al., 2021). When the truck was absent, the cattle were easier to move. Familiar sounds can also be used in a positive manner to encourage cow movement into a milking parlor. Over a period of 20 days, music on certain days was turned on when milking started and was turned off when milking ended. On the days the music played more, cows moved into the holding area that led to the parlor (Uetake et al., 1997).

\section{PROBLEMS WITH THE PHYSICAL ENVIRONMENT SUCH AS SLIPPING AND FALLING ON FLOORS AND RAMPS}

There are two types of problems that may cause slipping and falling. The first problem observed by the author is animals falling due to a slippery floor and the second is poor handling practices. Falling during handling is a definite welfare problem. It is included as a measurable outcome based welfare indicator by Grandin (1998), Welfare Quality Net (2009), Losada-Espinoza et al. (2018); OIE (2019); and NAMI (2021). A major problem with flooring is that it wears out slowly and people may not realize that the percentage of animals falling is increasing. This is why it is important to measure slipping and falling on a regular basis to determine if it is increasing. Another flooring problem is poorly designed cleats and flooring on ramps and unloading areas. On truck loading ramps, the spacing of the cleats should be spaced correctly. Cleats are horizontal narrow pieces of wood or steel that prevent livestock from slipping on ramps. The cleats (battens) need to be spaced so that an animal's foot can easily fit between them (Grandin, 2008). If they are too far apart, the animal's hoof will slip between the cleats (Figure 2). For large animals, such as, cattle, the cleats should have $20 \mathrm{~cm}$ of space between them (Grandin, 2008). The author has observed that weanling piglets may damage their rear dew claws if they are walking down ramps designed for cattle. When they slip, the dew claws may get caught on the widely spaced cleats that are designed for cattle.

It is stressful for pigs to walk up ramps that are too steep (Warriss et al., 1991). Garcia et al. (2019) found that a pig's heart will beat faster on a steep ramp. The maximum recommended angle for a cattle is $20^{\circ}$ (Grandin, 2008) and for pigs $15^{\circ}$ (Berry et al., 2012).

\section{VENTILATION AND FACILITY DESIGN FACTORS}

Another factor that is often overlooked is air movement in a handling facility. This explains why animals sometimes move

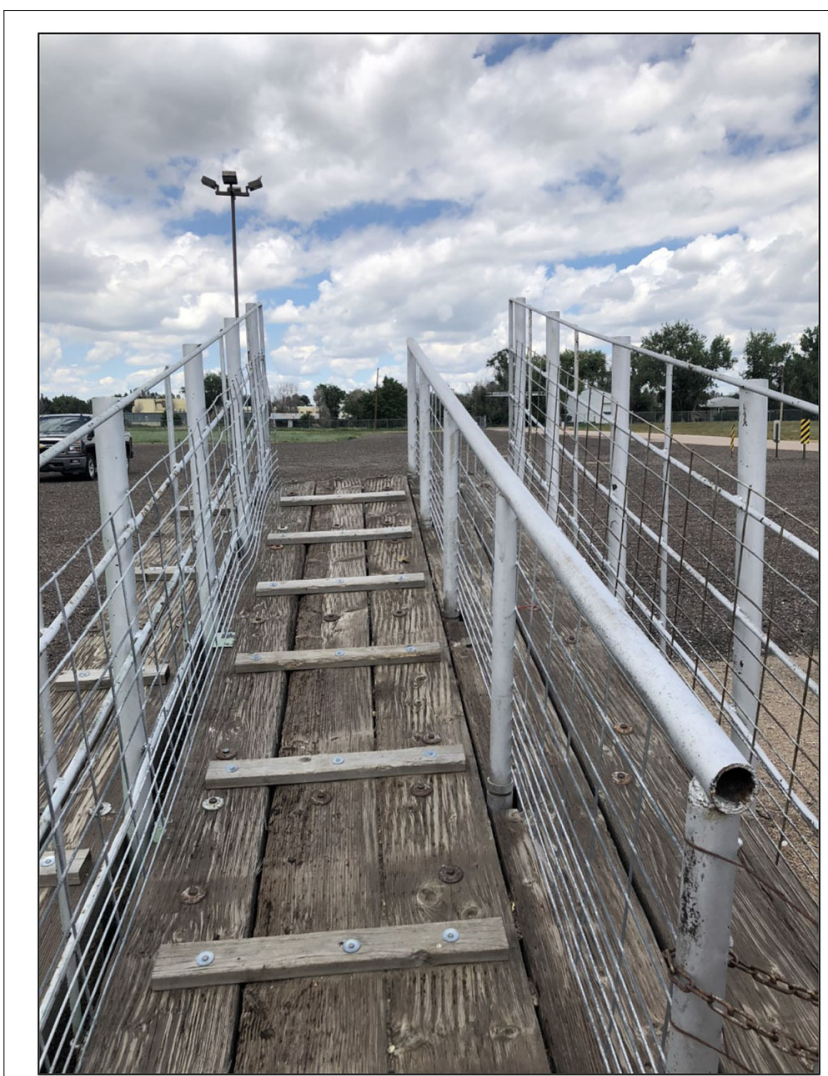

FIGURE 2 | Truck loading ramp for cattle that has cleats (battens) that are spaced too far apart. This will cause the hooves to slip. The cleats should be spaced so that an animal's hoof can easily fit between them. The addition of solid sides would prevent animals from seeing vehicles out in the parking lot. This may also improve animal movement.

easily into the stun box at an abattoir and at other times, they constantly stop and back up. Air blowing out the entrance stun box may cause livestock to stop. Changing the direction of the air flow at the stun box entrance reduced cattle vocalizing at the entrance due to electric prod use from $4.5 \%$ to $0 \%$. There are a few cattle or pig handling facilities that are so poorly designed that low stress handling is almost impossible. There are two worst design layout mistakes that will cause cattle or pigs to jam together in the system. A single file race that is too wide will make calm low stress handling extremely difficult. If it is one and a half animals wide, there will be constant jamming. Another serious mistake that can cause constant jamming is a crowd pen that has a funnel that is too gradual (Figure 3). Cattle will constantly jam in the gradual funnel.

\section{INDIVIDUAL DIFFERENCES IN THE BEHAVIOR OF PEOPLE AND ANIMALS}

\section{Behavior of Stock People}

When cattle, pigs or other livestock refuse to move, through a handling system, people are more likely to resort to using more aversive methods for moving them (Hultgren et al., 2020; Willson et al., 2021). Some examples of aversive methods are tail twisting 


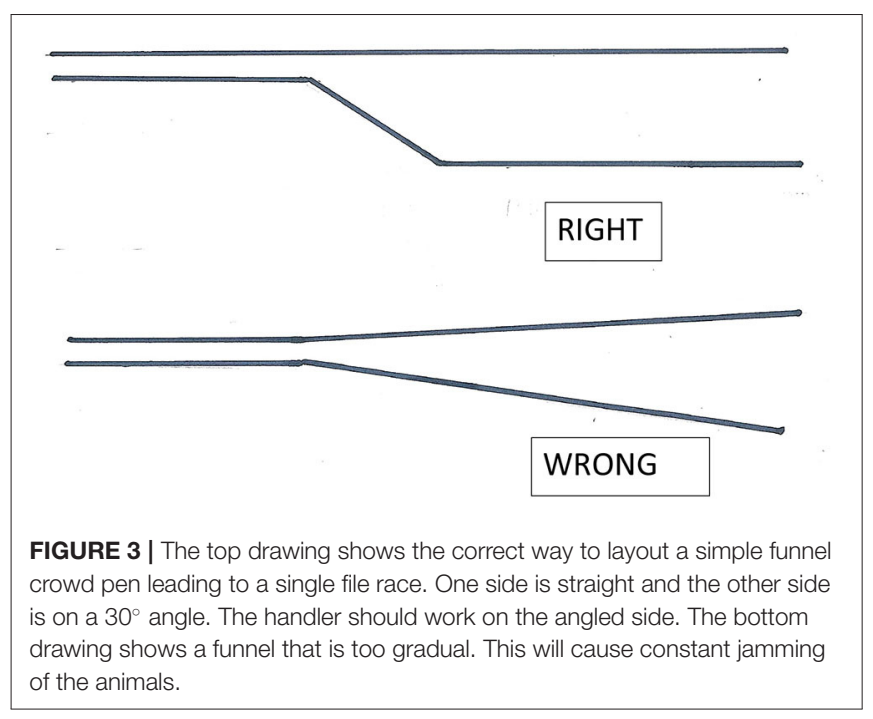

and beating. Grandin (2021) found that in an indoor facility, adding a light at the entrance of a race reduced electric prod use in pigs from $38 \%$ to $4 \%$. In cattle, illuminating the entrance of a conveyor restrainer also reduced the percentage of cattle that vocalized due to electric prod use. The percentage of cattle that vocalized during handling were reduced from $8 \%$ to $0 \%$ (Grandin, 2001). In this situation, the stock people had been specifically trained to only use the electric prod on cattle that had stopped moving. Training stock people in the basic behavioral principles of cattle handling will improve handling (Ceballos et al., 2018). The three most common mistakes people make when they handle cattle is putting too many animals in the crowd pen that leads to the single file race, making excessive noise, and standing in front of an animal when attempting to move it forward (Yost et al., 2020). Another factor that can increase stress is the use of dogs at slaughter houses. The use of dogs to move sheep through races and stockyards increased stress (Sutherland et al., 2016; Starling et al., 2021).

\section{Effect of Previous Experiences of the Animal on Livestock Handling}

An animal's willingness to move through a race or up a truck loading ramp is also influenced by its previous experiences. The problems caused by distractions, shadows, or noise are more likely to cause livestock to stop the first time they move through a new unfamiliar handling facility. Lewis et al. (2008) found that the heart rate was lower in pigs which were trained to move through alleys and ramps compared to the novelty of their first movement through the system. Pigs that have had regular experiences with being moved in the alleys will be easier to move in the future and less stressed by handling (Abbott et al., 1997; Geverink et al., 1998). Pigs that have become accustomed to having people walking through the fattening pens on the farm will often be easier to move at the abattoir. They have learned that when a person quietly walks through them they should get up and quietly move away (Grandin, 2021).

The author has observed at dairies that a new heifer may balk and refuse to walk over either a sunbeam or a drain.
An experienced cow will usually walk over it. Animals can be easily trained to move through handling facilities. Hutson (1985) and Paranhos de Costa et al. (2020) both report that providing feed rewards will facilitate movement of sheep and cattle through corrals and races. Research has also clearly shown that sheep, pigs, and other livestock can be easily trained to enter restraint devices for veterinary examinations, injections, and other procedures (Grandin, 1989; Fonseca et al., 2019; Lomb et al., 2021). Animals that are fully acclimated will have very low levels of physiological indicators of stress. Phillips et al. (1998) reported that Bongo antelope could be trained to voluntarily enter a box for blood sampling. They were rewarded with a favorite food.

Another factor the author has observed is that the methods for moving animals on the farm or ranch can have an effect on how they react when they are handled in a new place (Grandin, 2008). Extensively raised cattle that have been exclusively handled by riders on horseback may be more difficult and dangerous to move when they first see people walking on the ground, the horse and rider may be perceived as familiar and safe and people on the ground are novel and may be frightening. They may react to the novel person with an increased size of their flight zone. The cattle may allow the familiar horse and rider to approach much closer to them, compared to a person walking on the ground. This can be especially dangerous if the cattle are taken to an auction or slaughter plant where the cattle are handled by stock people walking. Leiner and Fendt (2011) reported that training a horse to tolerate a blue and white umbrella suddenly opening does reduce the startle reaction to a flapping canvas. Both this experiment and the research with the rotates child's playset indicate that the perception of horses is visually specific. It is likely that this is also true for cattle and other livestock. A person on a horse and a person walking on the ground look completely different.

\section{LAMENESS AND OTHER PHYSICAL ABNORMALITIES THAT MAY MAKE ANIMALS DIFFICULT TO MOVE}

Sometimes all species of livestock may be difficult to move and the problem is not associated with the visual, auditory or physical environment of the handling facility. The problems may be associated with either housing, diet, or an abnormality such as, lameness. The author has observed increasing problems with animals that are becoming more difficult to handle because they are reluctant to move. In some cases, this may be due to lameness. At a large pork slaughter plant there were differences in ease of handling based on farm of origin. The percentage of market weight pigs moved with an electric prod ranged from $20 \%$ to $4 \%$ (Grandin, 2021). These problems were not related to the environment in the handling facility, loading ramp or corral, or ability of stock people. At slaughter plants that process young fed cattle and pigs, some animals are stiff, lame, and reluctant to move. There is a combination of factors that may have contributed to this problem. Over the last 15 years, the author has observed that U.S. fed cattle are now heavier at a younger age. Three other factors are more genetic selection for 
meat traits, a lack of roughage in ruminant diets, and over use of growth promoters. In Italy, intensively finished Charolaise cattle had more foot disorders when they were fed high carbohydrate and low roughage diets (Magrin et al., 2020). Raising the cattle on concrete slats increased foot problems (Magrin et al., 2020). These problems often slowly became worse and people failed to notice it. The author calls this bad becoming normal. The detrimental condition increased slowly. When dairy producers were asked to estimate the percentage of lame cows in their herds, they underestimated by half (Leach et al., 2010; Bennett et al., 2014). A factor that may also contribute to lameness in fed beef cattle is housing for long periods on concrete slats (Wagner, 2016). High doses of beta-agonists can increase downed non-ambulatory pigs (Peterson et al., 2015), and hoof cracking (Poletto et al., 2009). High doses can also cause abnormal lying postures in fed cattle (Tucker et al., 2015). People who work in the lairage of beef abattoirs have observed that some fed young cattle from certain producers are reluctant to get up and difficult to move. Other livestock that are often difficult to move are old cull dairy cows because they are sometimes allowed to become skinny and debilitated. Unfortunately, there are still too many old cows that are in really poor condition when they reach the slaughter plant (Edwards-Callaway et al., 2018).

\section{OUTCOME BASED MEASURABLES TO ASSESS IMPROVEMENTS IN ANIMAL HANDLING AND MODIFICATIONS OF HANDLING FACILITIES}

Many government regulations, industry guidelines and commercial programs forbid aversive handling practices (EFSA, 2013a,b,c,d; OIE, 2019; FSIS/USDA, 2020; NAMI, 2021). Some examples of aversive practices are beating animals, poking sensitive areas or dragging conscious animals. The trend in animal welfare is to move away from specific input or engineering (resource) based standards and move to evaluating animal based outcome measures. A draft of the OIE slaughter standard calls them "measurable." Some of the measurable that have been used for years to evaluate the quality of handling practices are slipping and falling, electric prod use, and vocalization of cattle and pigs during handling (Grandin, 1998, 2001; Welfare Quality Net, 2009; Barnhardt et al., 2016; Woiwode et al., 2016; Bravo et al., 2019; OIE, 2019; NAMI, 2021). Adding a light to the entrance of a beef stun box reduced vocalization due to electric prod on cattle that refused to move from $8 \%$ of the cattle to $0 \%$ (Grandin, 2001). This is just one example how outcome based measurable can be used to assess the effectiveness of a simple change in lighting. Vocalization (bellowing in cattle, squealing in pigs) during handling restraint is associated with

\section{REFERENCES}

Abbott, T. A., Hunter, E. J., Guise, J. H., and Penny, R. H. C. (1997). The effect of experience of handling on pig's willingness to move. Appl. Anim. Behav. Sci. 54, 371-375. doi: 10.1016/S0168-1591(97)00045-2 physiological indicators of stress in cattle and pigs (Dunn, 1990; Warriss et al., 1994; Edwards et al., 2010; Hemsworth et al., 2011). High percentages of cattle vocalizing during handling are often due to electric prod use or excessive pressure applied by restraint devices (Grandin, 2001; Bourquet et al., 2011). Reducing pressure applied to a bovine's neck by a neck stanchion reduced the percentage of cattle vocalizing from $23 \%$ to $0 \%$ (Grandin, 2001). Each animal was scored as either vocalizing or silent. The advantage of the use of outcome measurable is that it becomes possible to track continuous improvement, if practices are improving, the numerical scores will reflect the improvements. Assessment on ranches and feedlots show that there are huge differences between the best and the worst operations (Grandin, 1998; Simon et al., 2015; Barnhardt et al., 2016; Woiwode et al., 2016). All three surveys showed that falling should be $1 \%$ or less. Woiwode et al. (2016) reported that the average percentage of cattle moved with an electric prod at large feedlots was 3.8\%. Many feedlots had $0 \%$ electric prod use and the worst place moved $45 \%$ of the cattle with an electric prod.

The use of measurable that assess outcomes can be used to evaluate both improvements in facilities and the effects of training on the behavior of stock people. Grandin (2001) collected data both before and after a facility was modified. The study clearly showed that simple modifications could reduce both cattle vocalization and electric prod use. Reducing pressure applied by a restraint device to a bovine's neck reduced vocalization from $23 \%$ of the animals to $0 \%$ (Grandin, 2001).

\section{CONCLUSIONS}

In existing races, stockyards, corrals, and veterinary facilities, simple improvements in the visual, auditory or physical environment will often improve ease of animal movement. In many cases, the facilities will not need to be completely rebuilt or remodeled. The removal of distractions, such as, noisy trucks near a lairage or reflections on shiny metal, may improve animal movement. Adding a light on a dark race entrance may reduce the tendency of cattle and pigs to stop and refuse to enter the race.

\section{DATA AVAILABILITY STATEMENT}

The original contributions presented in the study are included in the article/supplementary materials, further inquiries can be directed to the corresponding author/s.

\section{AUTHOR CONTRIBUTIONS}

The author confirms being the sole contributor of this work and has approved it for publication. 
Benjamin, M. E., Gonyou, H. W., Ivers, D. L., Richardson, L. F., Jones, D. J., Wagner, J. R., et al. (2001). Effect of handling method on the incidence of stress response in market swine in a model system [Abstract]. J. Anim. Sci. 79(Suppl. 1), 279.

Bennett, R., Barker, Z. E., Main, D. C. J., Whay, H. R., and Leach, K. A. (2014). Investigating the value dairy farmers place on a reduction of lameness in their herds using a willingness to pay approach. Vet. J. 199, 72-75. doi: 10.1016/j.tvjl.2013.09.068

Berry, N. L., Johnson, A. K., Hill, J., Longergan, S., Karriker, L. A., and Stalder, K. J. (2012). Loading gantry vs. traditional chute for finisher pigs, effect on welfare at the time of loading and performance measures and transport losses at the harvest facility. J. Anim. Sci. 90, 4028-4036. doi: 10.2527/jas.2011-4973

Bourquet, C., Deiss, V., Tannugi, C. C., and Terlouw, E. M. (2011). Behavioral and physiological reactions of cattle in a commercial abattoir: relationships with organization aspects of the abattoir and animal characteristics. Meat Sci. 88, 158-168. doi: 10.1016/j.meatsci.2010.12.017

Bravo, V. M., Knowles, T. G., and Gallo, C. (2019). Factors affecting the welfare of calves in auction markets. Animals 9:333. doi: 10.3390/ani9060333

Burnard, C. L., Pitchford, W. S., Hocking, J. E., and Hazel, S.J. (2015). Facilities, breed and experience affect ease of sheep handling-the livestock transporter's perspective. Animal 9, 1379-1385. doi: 10.1017/S1751731115000543

Carmargo, F., Bombeski, W. R., Barger, P., Jehlik, C., Wiemeus, H., Mead, J., et al. (2018). Epidemiology of equestrian accidents. Cogent. Food. Ag. 4. doi: 10.1080/23311932.2018.1432168

Ceballos, M. C., Sant'Anna, A. C., Boivin, X., de Oliveira, C. F., and Carvalhal, M. V. de L., et al. (2018). Impact of good practices of handling training on beef cattle welfare and stock people attitudes and behaviors. Livest. Sci. 216, 24-31. doi: 10.1016/j.livsci.2018.06.019

Corgan, M. E., Grandin, T., and Matlock, S. (2021). Evaluating the reaction to a complex rotated object in the American quarter horse (Equus caballus). Animals 11:1383. doi: 10.3390/ani11051383

Dunn, C. S. (1990). Stress reactions of cattle undergoing ritual slaughter using two methods of restraint. Vet. Rec. 126, 522-525.

Edwards, L. N., Grandin, T., Engle, T. E., Porter, S. P., Ritter, M. J., Sosnicki, A. A., et al. (2010). Use of exsanguination blood lactate to assess the quality of preslaughter handling. Meat Sci. 86, 384-390. doi: 10.1016/j.meatsci.2010.05.022

Edwards-Callaway, L. N., Walker, J., and Tucker, C. B. (2018). Culling decisions and dairy cattle welfare during transport to slaughter in the United States. Front. Vet. Sci. 5:343. doi: 10.3389/fvets.2018.00343

EFSA (2013a) Scientific opinion on monitoring procedures at slaughter houses for bovines. EFSA J. 11:3460. doi: 10.2903/j.efsa.2013.3460

EFSA (2013b). Scientific opinion on monitoring slaughter houses for poultry. EFSA J. 11:3521. doi: 10.2903/j.efsa.2013.3521

EFSA (2013c). Scientific opinion on monitoring procedures at slaughter houses for sheep and goats. EFSA J. 11:3522. doi: 10.2903/j.efsa.2013.3522

EFSA (2013d). Scientific opinion on monitoring procedures at slaughter houses for pigs. EFSA J. 11:3523. doi: 10.2903/j.efsa.2013.3523

Ercolano, H. (2018). Proceedings of the Animal Care Conference October 18-19 (Kansas: North American Meat Institute).

Fonseca, V. F. C., Saraiva, E. P., Maia, A. S. C., deMelo Costa, C. C., Guilherme, S., dos Santos, C. G., et al. (2019). Training sheep for indirect calorimetry trials. Small Rum. Res. 177, 36-43. doi: 10.1016/j.smallrumres.2019.06.010

Franklin, J. R., and Hutson, G. D. (1982). Experiments on attracting sheep to move along a laneway III visual stimuli. Appl. Anim. Ethol. 8, 457-478. doi: 10.1016/0304-3762(82)90059-1

FSIS/USDA. (2020). Humane Slaughter of Livestock Regulations 9 CFR 313. Washington, DC: USDA Food Safety Inspection Service.

Garcia, A., Johnson, A. K., Ritter, J., Calvo-Lorenzo, M. S., and McGlone, J. J. (2019). "Transport of market pigs improvements in welfare and economics," in Livestock Handling and Transport, eds T. Grandin (Wallingford, OX: CABI), 328-346. doi: 10.1079/9781786399151.0328

Geverink, N. A., Kappers, A., van de Burgwal, E., Lambooij, E., Blokhuis, J. H., and Wiegant, V. M. (1998). Effects of regular moving and handling on the behavioral and physiological responses of pigs to pre-slaughter treatment and consequences for meat quality. J. Anim. Sci. 76, 2080-2085.

Grandin, T. (1982). Pig behaviour studies applied to slaughter-plant design. Appl. Anim. Ecol. 9, 141-151. doi: 10.1016/0304-3762(82) 90190-0
Grandin, T. (1989). Voluntary acceptance of restraint by sheep. Appl. Anim. Behav. Sci. 23, 257-261. doi: 10.1016/0168-1591(89)90116-0

Grandin, T. (1996). Factors that impede animal movement at slaughter plants. $J$. Amer. Vet. Med. Assoc. 209, 757-759.

Grandin, T. (1998). Objective scoring of animal handling and stunning practices in slaughter plants. J. Amer. Vet. Med. Assoc. 212, 36-39.

Grandin, T. (2001). Cattle vocalizations are associated with handling and equipment problems in beef slaughter plants. Appl. Anim. Behav. Sci. 71, 191-201. doi: 10.1016/S0168-1591(00)00179-9

Grandin, T. (2008). Engineering and design of holding yards, loading ramps, and handling facilities for land and sea transport of livestock. Vet. Ital. 44, 235-245.

Grandin, T. (2021). “The importance of measurement to improve the welfare of livestock, poultry, and fish, improving animal welfare," in A Practical Approach, 3rd Edn, ed T. Grandin (Wallingford, OX: CABI), 19-45. doi: 10.1079/9781789245219.0019

Hawson, L. A., McLean, A. N., and McGreevy, P. D. (2010). The roles of equine ethology and applied learning theory in horse related human in juries. J. Vet. Behav. 5, 324-338. doi: 10.1016/j.jveb.2010.06.001

Hemsworth, P. H., Rice, M., Karlen, M. G., Calleja, L., Barnett, J. L., Nash, J., et al. (2011). Human-animal interactions at abattoirs: relationships between handling and animal stress in sheep and cattle. Appl. Anim. Behav. Sci. 135, 24-33. doi: 10.1016/j.applanim.2011.09.007

Hitchcock, D. K., and Hutson, G. D. (1979). Effect in variation in light intensity on sheep movement through narrow and wide races. Aust. J. Exper. Agric. Anim. Husbandry 19, 170-175. doi: 10.1071/EA9790170

Hultgren, J., Segerkvist, K. A., Berg, C., Karlsson, A. H., and Algers, B. (2020). Animal handling and stress-related behaviour at mobile slaughter of cattle. Prev. Vet. Med. 177:104959. doi: 10.1016/j.prevetmed.2020. 104959

Hutson, G. D. (1981). Sheep movement on slatted floors. Aust. J. Exper. Agric Anim. Husbandry 21, 474-479. doi: 10.1071/EA9810474

Hutson, G. D. (1985). The influence of barley food rewards on sheep movement through a handling system. Appl. Anim. Behav. Sci. 40, 263-273. doi: 10.1016/0168-1591(85)90007-3

Kilgour, R. (1971). “Animal handling in works: pertinent behavior studies," in Proceedings of the 13th Meat Industry Conference (Hamilton), 9-12.

Klinglmair, K., Stevens, K. B., and Gregory, N. G. (2011). Luminance and glare in indoor cattle handling facilities. Anim. Welf. 29, 263-269.

Lanier, J. L., Grandin, T., Green, R., Avery, D., and McGee, K. (2000). The relationship between reaction to sudden intermittent movements and sounds to temperament. J. Anim. Sci. 78, 1467-1474. doi: 10.2527/2000.7861467x

Laven, R. A., and Jermy, M. C. (2018). Measuring the torque required to cause vertebral dislocation in cattle tails. NZ. Vet. J. 68, 107-111. doi: 10.1080/00480169.2019.1685019

Leach, K. A., Whay, H. R., Maggs, C. M., Barker, Z. E., Paul, E., Bell, A. K., et al. (2010). Working toward a reduction in cattle lameness, 1.Understanding barriers to lameness control on dairy farms. Res. Vet. Sci. 89, 311-317. doi: 10.1016/j.rvsc.2010.02.014

Leiner, L., and Fendt, M. (2011). Behavioral fear and heartrate response of horses after exposure to novel objects effects of habituation, Appl. Anim. Behav. Sci. 131, 104-108. doi: 10.1016/j.applanim.2011.02.004

Lemmon, W. B., and Patterson, G. H. (1964). Depth perception in sheep: effects of interrupting the mother-neonate bond. Science 145, 835-836. doi: 10.1126/science.145.3634.835

Lewis, C. R. G., Hulbert, C. E., and McGlone, J. J. (2008). Novelty causes elevated heart rate and immune changes in pigs exposed to handling alleys and ramps. Livest. Sci. 116, 338-341. doi: 10.1016/j.livsci.2008.02.014

Lomb, J., Mauger, A., vonKeysleringk, M. A. G., and Weary, D. M. (2021) Effects of positive reinforcement training for heifers on responses to subcutaneous injections. J. Dairy Sci. 104, 6146-6158. doi: 10.3168/jds.2020-1 9463

Losada-Espinoza, N., Villarroel, M., Maria, G. A., and Miranda-de-la Lama, G. C. (2018). Pre-slaughter indicators for use in commercial abattoirs with voluntary monitoring systems: a systematic review. Meat Sci. 138, 34-48. doi: 10.1016/j.meatsci.2017.12.004

Lyvers, C. M. (2013). Evaluation of handling equipment sound, pressure levels as stressors in beef cattle, Theses and dissertations-biosystems and agricultural 
engineering paper 13 (thesis). University of Kentucky, Lexington, KY, U.S.A. Available online at: https://uknowledge.uky.ed/

Magrin, L., Brscic, M., Armato, L., Contiero, B., Lotto A, Cozzi G, et al. (2020). Risk factors for claw disorders in intensively finished Charolais beef cattle. Prev. Vet. Med. 175:104864. doi: 10.1016/j.prevetmed.2019.104864

Monk, J. E., Hine, B. C., Colditz, I. G., and Lee, C. (2018). A novel protocol to assess acclimation rate of Bos taurus heifers during yard weaning. Animals 8:51. doi: 10.3390/ani8040051

Muller, R., Schwartzkopf-Genswein, M. A., Shah, M. A., and vonKeyserlingk, M. A. G. (2008). Effect of neck injection and handler visibility on behavioral reactivity of beef steers. J. Anim. Sci. 85, 1215-1222. doi: 10.2527/jas.2007-0452

NAMI (2021). Recommended Animal Handling Guidelines and Audit, North American Meat Institute, Washington, DC. U.S.A. Available online at: https://www.Animalhandling.org/sites/default/files/forms/Animal_Handling Guide012021.pdf (accessed June 12, 2021).

OIE (2019). Chapter 7.5 Slaughter of Animals, Terrestrial Animal Health Code, Paris: World Organization for Animal Health.

Pajor, E. A., Rushen, J., and dePassille, A. M. B. (2003). Dairy cattle's choice of handling treatment in a Y-maze. Appl. Anim. Behav. Sci. 80, 93-107. doi: 10.1016/S0168-1591(02)00119-3

Paranhos de Costa, M. J. R., Huertas, S. M., and Gallo, C. (2020). Livestock Handling and Transport, 5th Edn, ed T. Grandin (Wallingford, OX: CABI Publishing), 184-205.

Pereira-Lima, M. L., Negrao-Cludia, J. A., Paro de Paz, C., and Grandin, T. (2018). Minor corral changes and adoption of good handling practices can improve the behavior and reduce cortisol release in Nellore cows. Trop. Anim. Health Prod. 50, 525-530. doi: 10.1007/s11250-017-1463-9

Peterson, C. M., Pilcher, C. M., Rothe, H. M., Marchant-Forde, J. N., Ritter, M. J., Carr, N., et al. (2015). Effect of feeding ractopomine hydrochloride on the growth performance and responses to handling and transport in heavy-weight pigs. J. Anim. Sci. 93,1239-1249. doi: 10.2527/jas.2014-8303

Phillips, M., Grandin, T., Graffan, W., Irlbeck, N. A., and Cambre, R. C. (1998). Crate conditioning of bongo (Tragelephus euryces) for veterinary and husbandry procedures at denver zoological gardens. 17, 25-32. Zoo Biolo. doi: 10.1002/(SICI)1098-2361(1998)17:1<25::AID-ZOO3>3.0.CO;2-C

Poletto, R., Rostagno, M. H., Richert, B. T., and Marchant-Forde, J. N. (2009). Effect of a "step up" ractopamine feeding program, sex, and social rank on growth performance hoof lesions, and Enterobacteriaceae shedding in finishing pigs. J. Anim. Sci. 87, 304-313. doi: 10.2527/jas.2008-1188

Sanchez-Hidalgo, M., Bravo, V., and Gallo, C. (2020). Behavior and health indicators to assess cull cow's welfare in livestock markets. Front. Vet. Sci. 7:471. doi: 10.3389/fvets.2020.00471

Simon, G. E., Hoar, B. R., and Tucker, C. B. (2015). Assessing cow-calf welfare, Part 1, benchmarking beef cow health and behavior during handling and management, facilities and producer perspective. J. Anim. Sci. 94, 3476-3487. doi: $10.2527 /$ jas.2016-0308

Starling, M. J., Payne, E., and McGreevy, P. (2021). Optional flow-a pilot study balancing sheep movement and welfare in abattoirs. Animals 11:344. doi: 10.3390/ani11020344

Stookey, M., and Watts, J. M. (2014). Low Stress Restraint and Handling of Beef Cattle, Livestock Handling and Transport, 4th Edn, ed T. Grandin (Wallingford, OX: CABI International), 65-78. doi: 10.1079/9781780643212.0065

Sutherland, M. A., Worth, G. M., Stuart, A. D., Dobbie, P. M., and Clerens, S. (2016). Effect of pre-slaughter handling, exercise and the presence of a dog on lamb welfare and meat quality. Animal 10, 1360-1367. doi: $10.1017 /$ S1751731116000197
Talling, J. C., Waran, N. K., Wathes, C. M., and Lines, J. A. (1998). Sound avoidance in domestic pigs depends on characteristics of the signal. Appl. Anim. Behav. Sci. 58, 255-266. doi: 10.1016/S0168-1591(97)00142-1

Tanida, H., Miura, A., Tanaka, T., and Yoshimoto, T. (1996). Behavioral responses of piglets to darkness and shadows. Appl. Anim. Behav. Sci. 49, 173-183. doi: 10.1016/0168-1591(96)01039-8

Tucker, C. B., Calvo-Lore3nza, M. S., and Mitloehner, F.M. (2015). Effects of growth promoting technology on feedlot cattle behavior 21 days before slaughter. Appl. Anim. Behav. Sci. 162, 1-8. doi: 10.1016/j.applanim.2014.11.001

Uetake, K., Hurnik, J. P., and Johnson, L. (1997). Effect of music on voluntary approach of dairy cows to an automatic milking system. Appl. Anim. Behav. Sci. 53, 175-182. doi: 10.1016/S0168-1591(96)01159-8

van Putten, G., and Elshof, W. J. (1978). Observations of the effects of transport on the well-being and lean quality of slaughter pigs. Anim. Regul. Stud. 1, 247-271.

Wagner, D. (2016). Behavioral analysis and performance responses of feedlot steers on concrete slats vs. rubber slats [Abstract] J. Anim. Sci. 94(Suppl. 5):31. doi: 10.2527/jam2016-0067

Warriss, P. D., Bevis, B. A., Edwards, J. E., Brown, S. N., and Knowles, T. G. (1991). Effect of angle on the ease with which pigs negotiate loading ramps. Vet. Rec. 128, 419-421. doi: 10.1136/vr.128.18.419

Warriss, P. D., Brown, S. N., and Adams, S. J. M. (1994). Relationship between subjective and objective assessment of stress at slaughter and meat quality in pigs. Meat Sci. 38, 329-340. doi: 10.1016/0309-1740(94)90121-X

Waynert, D. E., Stookey, J. M., Schwartzkopf-Genswein, J. M., Watts, C. S., and Waltz, C. S. (1999). Response of beef cattle to noise during handling. Appl. Anim. Behav. Sci. 62, 27-42. doi: 10.1016/S0168-1591(98)00211-1

Welfare Quality Net (2009). Assessment Protocols. Available online at: https://www. welfarequality.net/en-us/news/assessment-protocols (accessed June 12, 2021).

Willson, D. W., Baier, F. S., and Grandin, T. (2021). An observational field study on the effects of changes in shadow contrasts and noise on cattle movement in a small abattoir. Meat Sci. 179:108539. doi: 10.1016/j.meatsci.2021.108539

Woiwode, R., Grandin, T., Kirch, B., and Patterson, J. (2016). Compliance of large feedyards in the Northern high plains with beef quality assurance feedyard assessment. Prof. Anim. Sci. 32, 750-757. doi: 10.15232/pas.2015-01472

Yost, J. K., Yates, J. W., Davis, M. P., and Wilson, M. E. (2020). The stockman's scorecard: quantitative evaluation of beef cattle stockmanship. Trans. Anim. Sci. 4:txaa175. doi: 10.1093/tas/txaa175

Conflict of Interest: The author declares that the research was conducted in the absence of any commercial or financial relationships that could be construed as a potential conflict of interest.

Publisher's Note: All claims expressed in this article are solely those of the authors and do not necessarily represent those of their affiliated organizations, or those of the publisher, the editors and the reviewers. Any product that may be evaluated in this article, or claim that may be made by its manufacturer, is not guaranteed or endorsed by the publisher.

Copyright (c) 2021 Grandin. This is an open-access article distributed under the terms of the Creative Commons Attribution License (CC BY). The use, distribution or reproduction in other forums is permitted, provided the original author(s) and the copyright owner(s) are credited and that the original publication in this journal is cited, in accordance with accepted academic practice. No use, distribution or reproduction is permitted which does not comply with these terms. 